\title{
ARE THERE CORRELATIONS IN THE ACQUISITION OF DEFINITE PRONOUNS AND FINITE VERBS IN GERMAN?
}

\author{
Dagmar Bittner (ZAS, Berlin) \\ dabitt@zas.gwz-berlin.de
}

\section{Introduction}

The study presents a first investigation of two different processes in the L1-acquisition of German: The acquisition of definite pronominal forms and the occurence of finite verbs ${ }^{2}$. The aim of the study is to find out if there are inherent relations between both processes. Inherent relations are understood as developmental relations based on the structural properties which demand a correlated emergence of the finite verb and definite pronominal forms.

Studies on the acquisition of German noun morphology have shown that case and gender symbolization occures first on the definite article (Mills 1985, 1986; Müller 1994, 1999; Clahsen et al 1993, 1994). However, the original function of forms as die, der, den, dies, diese is not to symbolize case and gender (Bittner 1998). Definite forms like these are acquired in a very early period of language acquisition and are used in pronominal especially deictic functions. The analyses of the data of one German child as well as a first overview of other child data give rise to the assumption that the acquisition of definite pronominal forms is corellated with the acquisition of verb morphology - more precisely with the acquisition of the finite verb. Approximately at the same time as pronominal forms like die and der occur, one can observe an increase in the use of finite verbs. Finite verb forms are not longer restricted to a small group of verbs dominantly used in frozen or idiomatic patterns of utterances.

The question is if the corellation between both processes is accidental or if structural grammatical relations exist. It has to be asked if the correlation is based on grammatical aspects, such as:

- language specific conditions resulting from specific properties of definite pronouns and finite verbs in German,

- typological conditions (not all languages possess definite pronouns),

- universal grammatical conditions.

To answer these questions demands much more extensive studies especially on the acquisition of definite pronouns and on their relation to the acquisition of finite verbs as have done till now. Because of that resultative answers have to be left to the future.

I would like to thank Insa Guelzow for helpful discussions of the present paper and for taking my English under observation.

2 Of course, there are different investigations of the acquisition of finite verbs in German, cf. Clahsen (1991), Clahsen et al (1993), Schlyter (1990), Meisel (1990), Behrens (1993). In difference to these detailed analysis the present paper takes in to consideration only time of occurence and productive use of finite verbs. 
First of all it has to be shown that the observed correlation is not accidental. This could not assumed as beeing trivial. In the early phases of language acquisition covering the period of one word utterances to the regularly use of multi word utterances or more precisely multi phrase utterances nearly everything is increasing in child language: the lexicon, the complexity of the utterance, the grammar of verb and noun phrases, the grammar of sentence structure etc. In this way different structures occur at the same time. Not all of them will be structuraly related, for instance it is not very likely that the acquisition of number inflection on nouns is related to the increase of the verb lexicon or the acquisition of adjectives. Whether parallel processes in language acquisition are structurally related has to be proved in every single case.

This paper is devided in four parts:

1. the course of the acquisition of definite pronouns in the data of the child Anna,

2. the occurence of finite verbs in the data of Anna and the correlations to her acquisition of definite pronouns,

3. brief discussion of the acquisition of NPs in subject position in the data of Anna,

4. discussion of the observed structural relations between the investigated processes.

The hypothesis is that the acquisition of finite verbs triggers the acquisition of an overt marking of the subject position. Definite pronouns fullfill the prototypical thematic properties of subjects and are semantically as well as structurally accessible enough to match the child's abilities in building complex utterances in the beginning of the production of multi phrase utterances. Definite pronouns (beside proper names and personal pronouns) are ideal candidates for this syntactical position.

\section{The data}

The data analysed in the present study are longitudinal data of the girl Anna in the age range of 1;08:10 - 2;01:27 covering 8 recordings (table 1 ). ${ }^{3}$ The recorded situations mainly took place at Anna's home where she played with her own toys, participated is kitchen work or dinner situations. Anna is the only child in a middle class family living in Berlin. The parents speak standard high German with only a few phonological elements of the Berlin variety. Since the age of 1;0 Anna regularly visited the kindergarten.

\footnotetext{
The data were audio- and partly videotaped by myself and were transcribed by Franziska Bewer.
} 
Table 1: data of Anna

\begin{tabular}{|c|c|c|}
\hline age & time of recording (in minutes) & utterances of Anna ${ }^{4}$ \\
\hline $1 ; 08: 10$ & 65 & 294 \\
\hline $1 ; 08: 29$ & 57 & 220 \\
\hline $1 ; 09: 14$ & 75 & 239 \\
\hline $1 ; 10: 00$ & 61 & 293 \\
\hline $1 ; 11: 06$ & 70 & 338 \\
\hline $2 ; 00: 05$ & 51 & 304 \\
\hline $2 ; 00: 29$ & 94 & 608 \\
\hline $2 ; 01: 27$ & 89 & 571 \\
\hline
\end{tabular}

\section{The acquisition of definite pronouns}

\subsection{The adult system of definite pronouns}

In the period of time investigated in the present paper Anna is using predominantly pronominal forms of das, der and die which are gender related forms (das $=n t r, d e r=m s c$, die $=$ fem and plural of all genders). Only 7 instances of other types of pronouns occure, these are 4 forms of diese/dieser and 3 forms of the phonological reduced form de. Then, in the case of Anna we can concentrate on the pronominal use of das, der, and die. In adult language the forms of der, die, das are preferably used as demonstrative pronouns in anaphoric or cataphoric relation where theire reference is determined by the language context. All forms could be used as deictic demonstrative pronouns which means to refer to objects given in the situation but not in language context. The most common form for this is das. Beside gender the forms are inflected for case and number. Table 2 presents the paradigm system.

Table 2: paradigm system of the pronouns der, die, das

\begin{tabular}{c|cccc} 
& msc & ntr & fem & plural \\
\hline nomin. & der & das & die & die \\
genit. & dessen & dessen & deren & deren \\
dative & dem & dem & der & denen \\
accus. & den & das & die & die
\end{tabular}

It should be mentioned that Anna did not acquire genitive and dative forms in the investigated time span. This is in accordance with various studies on the acquisition of case marking in German (cf. Mills 1986, Clahsen et al 1994). The order of acquisition of case forms found out in these studies is: nominantive $>$ accusative $>$ dative $>$ genitive. Genitive occures hardly before $3 ; 0 .^{5}$

4 Completely ununderstandable utterances of Anna and utterances including onomatopoetics only as well as $j a$ 'yes', nein 'no' or $h m$ and so on are not counted here.

5 I do not agree to consider possessive marking such as anna-s buch 'Anna's book' or mama-s hut 'mama's hut' as genitives. Beside the very early occurence of possessives in contrary to the very late occurence of genitives in language acquisition the main argument is that possessives in adult grammar can co-occur in 


\subsection{The occurence of das, der, die in the data of Anna}

Table 3 presents the token numbers of the different definite pronouns occuring in Anna's data per recording. They are divided into self-produced forms (first number) and total amount of tokens (second number). Forms were coded as "self-produced" if they were not an immediate imitation of an adult form or an element of a frozen pattern, part of a song or a poem.

Table 3: definite pronouns in the data of Anna (self-produced forms/total number)

\begin{tabular}{|l|c|c|c|c|c|c|c|c|}
\hline age & $1 ; 08: 10$ & $1 ; 08: 29$ & $1 ; 09: 14$ & $1 ; 10: 00$ & $1 ; 11: 06$ & $2 ; 00: 05$ & $2 ; 00: 29$ & $2 ; 01: 27$ \\
\hline die & & & $1 / 1$ & $1 / 1$ & $1 / 1$ & $1 / 2$ & $7 / 13$ & $9 / 13$ \\
\hline der & $-/ 2$ & $-/ 2$ & & $1 / 1$ & $1 / 3$ & $4 / 15$ & $6 / 8$ & $16 / 24$ \\
\hline das & $3 / 14$ & $4 / 8$ & $2 / 5$ & $19 / 23$ & $20 / 27$ & $26 / 33$ & $10 / 17$ & $85 / 100$ \\
\hline de & $1 / 1$ & & $1 / 1$ & & & & $-/ 1$ & \\
\hline den & & & $1 / 1$ & $1 / 1$ & & & $1 / 2$ & $2 / 2$ \\
\hline dies- & & $1 / 1$ & & & & & $2 / 2$ & $1 / 1$ \\
\hline
\end{tabular}

As one can see Anna has already started with the acquisition of definite pronouns at 1;08:10. It is obvious from the first three recordings that Anna has learnt about the existence of different forms of definite pronouns. Up to 1;09:14 she is using a small amount of forms, predominantly the form das. The recording at $1 ; 10: 00$ seems to document the beginning of a new phase in the acquisition process: Anna has developed a clear preference for the das form. Other forms hardly occur, whereas das is used more frequently then before. Still the same situation is found in the next recording at 1;11:06. From 2;00:05 on Anna also uses the forms der and die more regularly. In the two last recordings the use of der and die seems to increase further.

In order to check if the development in the acquisition of definite pronouns suggested by the numerical analyses above is not an artefact of different amounts of utterances per recording the procentual amount of utterances with das, with der, and with die out of the number of Annas utterances per recording is shown in chart 1. The few occurencies of the other definite pronouns (table 3 ) are not considered in chart 1.

combination with other cases, cf. sie gab den Knochen Peters Hund 'she gave the bone to peter's dog'. A main feature of paradigmatic categories such as case, number, and gender are their alternative distribution which makes co-occurence impossible. 
chart 1: utterances with das, der, die (\%)

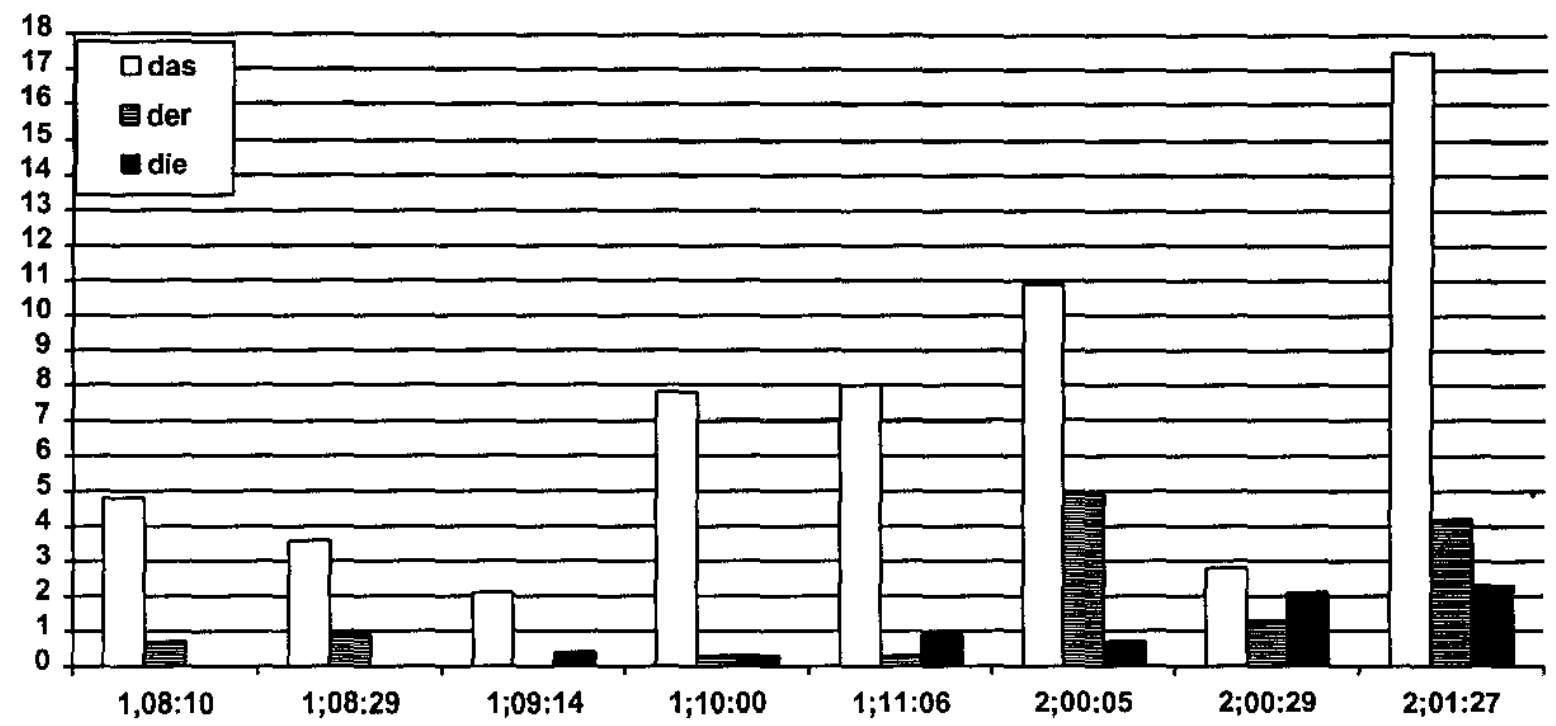

The impression given by chart 1 confirms the interpretation of the data of Table 3 . The first three recordings are characterized by an only spontaneous appearance of der and die. Das is used regularly but only in a small amount of utterances. Its use increases noticeably in the next two recordings at 1;10:00 and 1;11:06 whereas the use of die and der remains very low. This impression changes from 2;00:05 on, die and der seem to belong to Annas regular language inventory occuring in at least $3 \%$ of her utterances.

To summarize both parts of the analysis we can describe 3 phases in the acquisition of definite pronouns by Anna in the investigated time span:

- phase I (1;08:10 - 1;09:06): first occurences of different definite pronouns, rare use;

- phase II $(1 ; 10: 00-1 ; 11: 06)$ : establishing das as the dominant form, productive use;

- phase III (2;00:05 - 2;01:27): increasing use of der and die up to productive use.

The order of acquisition up to 2;01:27 is: das > der/die. In order to answer the question which function these forms have in Anna's grammar the next chapter will deal with the syntactic contexts in which they occur.

\subsection{Syntactic contexts of early das, der, and die}

In accordance with the aim of the investigation to find out if there are correlations between the acquisition of definite pronouns and the acquisition of finite verbs the following syntactical contexts of definite pronouns have been distinguished:

- utterances without a verb $(-\mathrm{V})$,

- utterances with nonfinite verbs $\left(+\mathrm{V}_{\text {inf, }}\right.$ e.g. a verb ending in -en with no clear agreement relation),

- utterances with finite verbs where in the definite pronoun is not in agreement with the verb $\left(+\mathrm{V}_{\text {fin }} /-\mathrm{Agr}\right)$ 
- utterances with finite verbs where in the definite pronoun is in agreement with the verb $\left(+\mathrm{V}_{\mathrm{fin}} /+\mathrm{Agr}\right)$.

Tables 4-6 show the development of the distribution of das, der, and die in the proposed syntactic contexts. ${ }^{6}$

Table 4: syntactic contexts of das

\begin{tabular}{|c|c|c|c|c|c|}
\hline phase & age & $-\mathrm{V}$ & $+\mathrm{V}_{\text {inf }} / \mathrm{Agr}$ & $+\mathrm{V}_{\mathrm{fin}} /-\mathrm{Agr}$ & $+\mathrm{V}_{\mathrm{fin}} /+\mathrm{Agr}$ \\
\hline \multirow[t]{3}{*}{ I } & $1 ; 08: 06$ & 3 & & & 1 \\
\hline & $1 ; 08: 29$ & 4 & & & \\
\hline & $1 ; 09: 14$ & 2 & & & \\
\hline \multirow[t]{2}{*}{ II } & $1 ; 10: 00$ & 18 & 1 & & \\
\hline & $1 ; 11: 06$ & 15 & 4 & $1\left(1 \operatorname{cop}^{7}\right)$ & \\
\hline \multirow[t]{3}{*}{ III } & $2 ; 00: 05$ & 19 & & $7(5 \mathrm{cop})$ & \\
\hline & $2 ; 00: 29$ & 4 & 1 & $4(2 \mathrm{cop})$ & 1 \\
\hline & $2 ; 01: 27$ & 20 & 2 & 50 (31 cop) & 13 \\
\hline
\end{tabular}

Table 5: syntactic contexts of der

\begin{tabular}{|c|c|c|c|c|c|}
\hline phase & age & $-\mathrm{V}$ & $+\mathrm{V}_{\text {inf }} /$ Agr & $+\mathrm{V}_{\mathrm{fin}} /-\mathrm{Agr}$ & $+\mathrm{V}_{\mathrm{fin}} /+\mathrm{Agr}$ \\
\hline \multirow{5}{*}{ I } & $1 ; 08: 06$ & & & & \\
\cline { 2 - 6 } & $1 ; 08: 29$ & & & & \\
\hline & $1 ; 09: 14$ & & & & \\
\hline \multirow{3}{*}{ II } & $1 ; 10: 00$ & & & & $\mathbf{1}$ \\
\hline \multirow{3}{*}{ III } & $1 ; 11: 06$ & & & & $\mathbf{3}$ \\
\hline & $2 ; 00: 05$ & $\mathbf{3}$ & & & $\mathbf{1}$ \\
\hline & $2 ; 00: 29$ & $\mathbf{3}$ & $\mathbf{2}$ & & $\mathbf{1 8}$ \\
\hline & $2 ; 01: 27$ & $\mathbf{1}$ & & & \\
\hline
\end{tabular}

Table 6: syntactic contexts of die

\begin{tabular}{|c|c|c|c|c|c|}
\hline phase & age & -V & +Vinf/-Agr & +Vfin/-Agr & +Vfin/+Agr \\
\hline \multirow{3}{*}{ I } & $1 ; 08: 06$ & & & & \\
& $1 ; 08: 29$ & & & & \\
& $1 ; 09: 14$ & & $\mathbf{1}$ & & \\
\hline \multirow{2}{*}{ II } & $1 ; 10: 00$ & $\mathbf{1}$ & & & \\
& $1 ; 11: 06$ & & $\mathbf{1}$ & & \\
\hline \multirow{2}{*}{ III } & $2 ; 00: 05$ & & & $\mathbf{1}$ & \\
\cline { 2 - 6 } & $2 ; 00: 29$ & $\mathbf{1}$ & $\mathbf{2}$ & $\mathbf{3}$ & $\mathbf{7}$ \\
\hline & $2 ; 01: 27$ & $\mathbf{3}$ & & $\mathbf{1}$ & $\mathbf{6}$ \\
\hline
\end{tabular}

In phase I when Anna is using only a small number of definite pronouns all forms except of 2 occur in utterances without a verb. Predominantly this is ' $d a s^{\prime}$ ' forming a complete one word utterance. The two exceptions are one form in agreement with the verb:

6 In these tables all utterances with definite pronouns that are not imitated in their main structural parts were counted. Which means that utterances with imitated definite pronouns were counted if the same utterance contained central elements which were not imitated - like e.g. the verb.

7 The proportion of das occuring together with the sein-copula are given in brackets, cf. das ist heiß 'it is hot', das ist mama 'it is mama'. 
(1) das schaukelt 'it is swinging'

and one form accompanying an infinite verb representing a patient element:

(2) gucken die 'looking at this/these'

Phase II is characterized by the already mentioned fact that Anna has established $d a s$ as the dominant definite pronoun. This form is now used for clearly deictic demonstrative purposes. In nearly all utterances where das is used without a verb the complete utterance is:

(3) das hier

'this here'

As one can see from table 4-6 in phase II Anna is also starting to use definite pronouns in utterances containig verbs. 6 out of the 9 definite pronouns are das again accompanyed by hier in three cases. In 5 of the 6 utterances with das the verb is infinite and the das-phrase represents a patient element:

(4) das hier haben

das hier \# hochsetzen

das auch auspacken $(2 \mathrm{x})$

das auch abmachen 'want to have this here'

'put up this here'

'unwrap this/that too'

'take off this/that too'

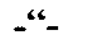

-“"-

In phase II only one other definite pronoun occurs in the same structur, and this is probably a nontarget use of die instad of das:
(5) die abmachen
'take it/this off'

3 of the 9 definite pronouns in verb containing utterances of phase II occur with a finite verb. In one case das is combined with the 3.ps.sg.-form of the copula sein 'to be' which is ist 'is'. There is no number agreement between both elements. As in adult language das is used in copula constructions as a purely deictic demonstrativ without a specified object reference:

(6) ist das hier?

'(what) is this here?'

With a finite verb but in agreement with the verb Anna uses only der two times in phase II:
(7) der ist es, den
'it (the crayon) is it, this'
$(1 ; 10: 00)$
der sitzt dort
'he (the bear) is sitting there'

Obviously phase II is different from phase I not only by the establishing of das as a productive deictic demonstrative pronoun but also by the beginning of a combined use of definite pronouns and verbs. First this mirrors that Anna has started to produce more complex utterances: In 1;10:00 she is producing about 50 utterances with more than two words. These are around $18 \%$ of her total amount of utterances. In the preceding interview at 1;09:14 belonging to phase I only about $4 \%$ of Anna's utterances are build of more than two words. 
However, the question is what types of definite pronouns occur in what kind of utterances. This could be answered looking at phase III.

In phase III das is used preferably in utterances without a verb (-V) and in utterances containig a finite verb but whithout an agreement relation with the verb (+V/-Agr). As can be seen in table 4 the $+\mathrm{V}_{\text {fin }}$-Agr utterances with das are divided into two different types: utterances including a lexical verb where das has the patient role or accusative position (8) and copula constructions with das (9):

(8)

ich mach das

das hier (ge)sagt

Lucas hat das mit(ge)bracht

(9) das ist?

meine mama war das

das ist auch kaffee
'I do it'

' $\mathrm{X}$ has said it'

'Lucas has brought it'

'(what) is this/that?'

'this/that was my mama'

'this/that is also coffee'

The first copula construction with das appeared at 1;10:00. In the three recordings up to 2;00:29 Anna produces in sum only 8 such constructions. In 2;01:27 an explosion of these structure occures. 31 utterances with das and sein-copula without agreement relation are documented, that are $36 \%$ of all das tokens in this recording.

The context $+V_{\text {inf }}$-Agr represents nontarget use of infinitives as the examples in (4) have shown. Although no definite statement is possible the data suggest that this structure decreases in phase III. According to different studies of verb acquisition (cf. foot note 1) and as will be discussed in the next chapter this is the expectable development.

The syntactical context $+\mathrm{V}_{\mathrm{fin}} /+\mathrm{Agr}$ represents utterances where the definite pronoun occupies the subject position. Anna nearly never uses das in this structure up to 2;00:29. Then, in the last recording at 2;01:27 15\% of all das tokens occure in this structure.

(10) wo ist das?

das klingelt schon wieder

das kommt hier hin 'where is it?'

'it is ringing again'

'it has to be here'
(2;01:27)

$-6$

-"

Hardly any of the das occurencies have a concrete object reference. One can summarize that das is acquired by Anna as a general demonstrative to refer to all kinds of things given in the communicative situation. In phase III Anna expands the originally purely deictic reference to the reference to complex things not visible in the communicative situation, cf. die macht das auch so gern 'she too likes to do it' $(2 ; 00: 29)$ and to introduce the naming of things or properties, cf. the examples in (8) or das ist mama 'it is mama', das ist nicht heiß 'it isn't hot' $(2 ; 01: 27)$. This development is not a development of the functional content of das. What has developed are Annas cognitive abilities and her abilities to produce more complex utterances and different types of utterances. The function of das to symbolize the reference to 
an element of the communicative context, which means a deictic reference, does not change in the investigated period of time.

The definite pronouns der and die are used by Anna more frequently only in phase III. Der appeares in utterances without verbs $(-V)$ and in utterances where it is in agreement with the finite verb $\left(+\mathrm{V}_{\mathrm{fin}} /+\mathrm{Agr}\right)$. Der never occurs in $+\mathrm{V}_{\mathrm{fin}} /$-Agr utterances and nearly never in $+\mathrm{V}_{\text {inf }}$ f -Agr (table 5).

$$
\begin{aligned}
& \operatorname{der}(=\text { vogel }) \\
& \operatorname{der}(=\text { stift }) \text { auch? }
\end{aligned}
$$

$$
\begin{aligned}
& \text { 'it(=beard)' } \\
& \text { 'it(=crayon) to' }
\end{aligned}
$$

(12) $\operatorname{der}(=$ spielfigur) auch losfährt 'he(=toy man) starts to drive to' piep piep macht der (=rabbit) 'it(=rabbit) is saying piep piep' $\operatorname{der}(=$ Peter $)$ soll hier sitzen 'he(=Peter) should sit down here'

From early on der seems to be clearly restricted to the subject position as it is the case in adult language. The 11 utterances with $d e r$ in frozen patterns (not included in table 5) support this functional specification, $\mathrm{cf}$ :

(13)

$\begin{array}{ll}\text { der paßt hin } & \text { 'it fits there' } \\ \text { der geht } & \text { 'it works' } \\ \text { der geht gar nicht } & \text { 'it doesn't work }\end{array}$

And der occures as well as the potential subject element ${ }^{8}$ in utterances without a verb or with an infinite verb, cf.:

(14) $\operatorname{der}$ (=spielfigur) (hat) paddel auch 'he(=toy man) too (has) a paddle'

$\operatorname{der}(=$ spielfigur) auch wasser 'he(=toy man) too into the water'

(=der geht auch ins w.)

(he too is going into the water)

weil der $(=$ wolf $)$ nicht wegpusten

'because he(=wulf) not blow away' $(2 ; 00: 29)$

$\operatorname{der}(=$ frosch $)$ hüpfen

'it(=frog) frisk'

Anna starts to use die more regularly from 2;00:29 on. Comparable to der die occures most frequently in $+\mathrm{V}_{\mathrm{fin}} /+$ Agr utterances where it is the potential subject element, $\mathrm{cf}$.:

(15) wasser gehen die(=spielfiguren $)^{9} \quad$ 'they(=toy figurs) are going into the water' $(2 ; 00: 29)$

8 I don't want to talk about subjects, because Anna probably in this early phase is not aware or has not acquired the grammatical distinction between subject and object. Her understanding of these elements would be predominantly a semantic one in the sense of the agent or the theme of the predication.

9 It seems to be hard to decide how to count occurences of die in utterances where the verb is ending in -en (cf. also die stehen 'she/they is/are standing', wasser gehen die 'they are going (into) the water'). In adult German the 1./3.Pl. is homonymous with the infinite form. For two reasons I counted the verb in these utterances as finite: a) there was no evidence that Anna is matching sg. and pl. agreement with die and b) when Anna starts to use die in subject position, she also starts to use $2 . \mathrm{sg}$. forms of verbs (cf. du ißt das? 'you eat that?', du hast 'you have'). The studies on verb acquisition have shown that the 2.sg. form is one of the last steps in the acquisition of agreement inflection. Agreement with 1./3. pl. forms occures usually in before. 


$$
\begin{aligned}
& \text { die }(=f r a u) h e i \beta t ? \\
& \text { die }(=k n e t e) k l e b t
\end{aligned}
$$

$$
\begin{aligned}
& \text { '(what)'s her(=woman) name?' } \\
& \text { 'it(=modelling clay) sticks' }
\end{aligned}
$$

In contrary to der it occures as well in +Vfin/-Agr-utterances. In this structure die is the potential object element and this is in correspondance with the adult system: .

$$
\begin{aligned}
& \operatorname{die}(=\text { gummistiefel) anziehen will 'want to dress them(=gumboots)' } \\
& \text { die (=ente) find ich nicht } \\
& \text { ich pack die(=?) hin } \\
& \text { 'I don't find it(=duk)' } \\
& \text { 'I putt down it/them(=?)' }
\end{aligned}
$$

What is crucial is the fact that die occurs clearly more frequently in the potential subject position then in the potential object position (cf. the last two columns of table 6). When it is used as a potential object element it tends to occupy the first position in the utterance. Out of the total of 9 utterances containing die and a verb but no agreement between them in 6 times die is the first element of the utterance, cf. the examples in (16).

\subsection{First conclusions}

Although one can observe only the first steps in the acquisition of die and der in the investigated data one can conclude that die and der are acquired at a different stage in language acquisition than das. As mentioned above they occure when Anna is already able to produce multi-word utterances containing two ore more syntactical phrases. At 2;00:05 25\% of her utterances contain more than two words. One third of these consists of more than three words and all of the latter include more than two syntactical phrases.

These complex utterances require the distinction between new and old information, between theme and focus elements. In comparison to English and other languages German exhibits a differentiated system of definite pronouns to refer to old or already known elements. The child learns from the input that das as the first definite pronoun which she has acquired does not fit all contexts to refer to known elements. For instance, das lacks the possibility to refer to already mentioned language elements. It was acquired for deictic reference and lacks anaphoric potential. Der and die are acquired to fulfill the requirements of a more specified reference relation. Their function is not primarily a deictic one but is related to the language context.

A central feature of anaphoric reference in German is agreement with the anteceding element. Agreement seems to be the central aspect of the differentiation of the definite pronouns in German. Agreement is also required for subjects in utterances with finite verbs. The analysis of the syntactic contexts of der and die has shown that the first occurences of both forms are mainly occurences in subject position, cf. the $+\mathrm{V}_{\mathrm{fin}} /+$ Agr. contexts in table 5 and 6.

It can be expected that the acquisition of finite verbs plays a crucial role in the implementation of agreement requirements for definite pronouns in early grammar. The occurence of finite verbs in Anna's data will be analysed in the following chapter. 


\section{The acquisition of the finite verb ${ }^{10}$}

\subsection{The adult system of person and number inflection}

In the investigated period of time Anna uses the following types of verbs:

a) lexical verbs in present tense

b) sein-copula in present and past tense

c) modal verbs in present tense

The person-/number-paradigms of these verbs in adult German are as follows:

Table 7: person-/number-inflection of lexical verbs (example: machen 'to do')

\begin{tabular}{l|cc} 
& singular & plural \\
\hline 1. person & mach-e & mach-en \\
2. person & mach-st & mach-t \\
3. person & mach-t & mach-en
\end{tabular}

Table 8: person-/number-forms of seincopula in present tense

\begin{tabular}{l|cc} 
& singular & plural \\
\hline 1. person & bin & sind \\
2. person & bist & seid \\
3. person & ist & sind
\end{tabular}

Table 9: person-/number-forms of seincopula in past tense

\begin{tabular}{l|cc} 
& singular & plural \\
\hline 1. person & war & waren \\
2. person & warst & wart \\
3. person & war & waren
\end{tabular}

Table 10: person-/number-forms of modal verbs (example: können 'can')

\begin{tabular}{l|cc} 
& singular & plural \\
\hline 1. person & kann & könn-en \\
2. person & kann-st & könn-t \\
3. person & kann & könn-en
\end{tabular}

\subsection{The occurence of finite verbs in the data of Anna}

At the beginning of the recordings Anna was already using finite forms of verbs. In nearly all cases these are the 3.ps.sg.pres.ind. of lexical verbs. ${ }^{11}$ In the first 3 recordings $(1 ; 08: 10$ $1 ; 09: 14)$ the portion of self-produced finite forms out of all self-produced verb forms is between $35 \%$ and $44 \%$ (without imitations, verbs in frozen patterns, songs, rhymes ec.). In the following two recordings $(1 ; 10: 00-1 ; 11: 06)$ this amount decreases to $25 \%$. From $2 ; 00: 05$ on the use of finite verbs lies over the $45 \%$ mark and increases up to $70 \%$ in the recording at

10 "finite verb" is used here as a term for verbs inflected for person and number. What finiteness XXX

11 There are only 2 utterances with possibly other person/number-forms: schlafen alle $(1 ; 08: 29)$, gucken die $(1 ; 09: 14)$. Because of the lack of further finite forms in other categories than 3.sg. I don't count these phrases as finite. 
2;01:27. Chart 2 shows the proportion of self-produced finite verbs as a developmental curve over the investigated period of time (bold line). Additionally the total share of utterances containig a verb is given (thin line).

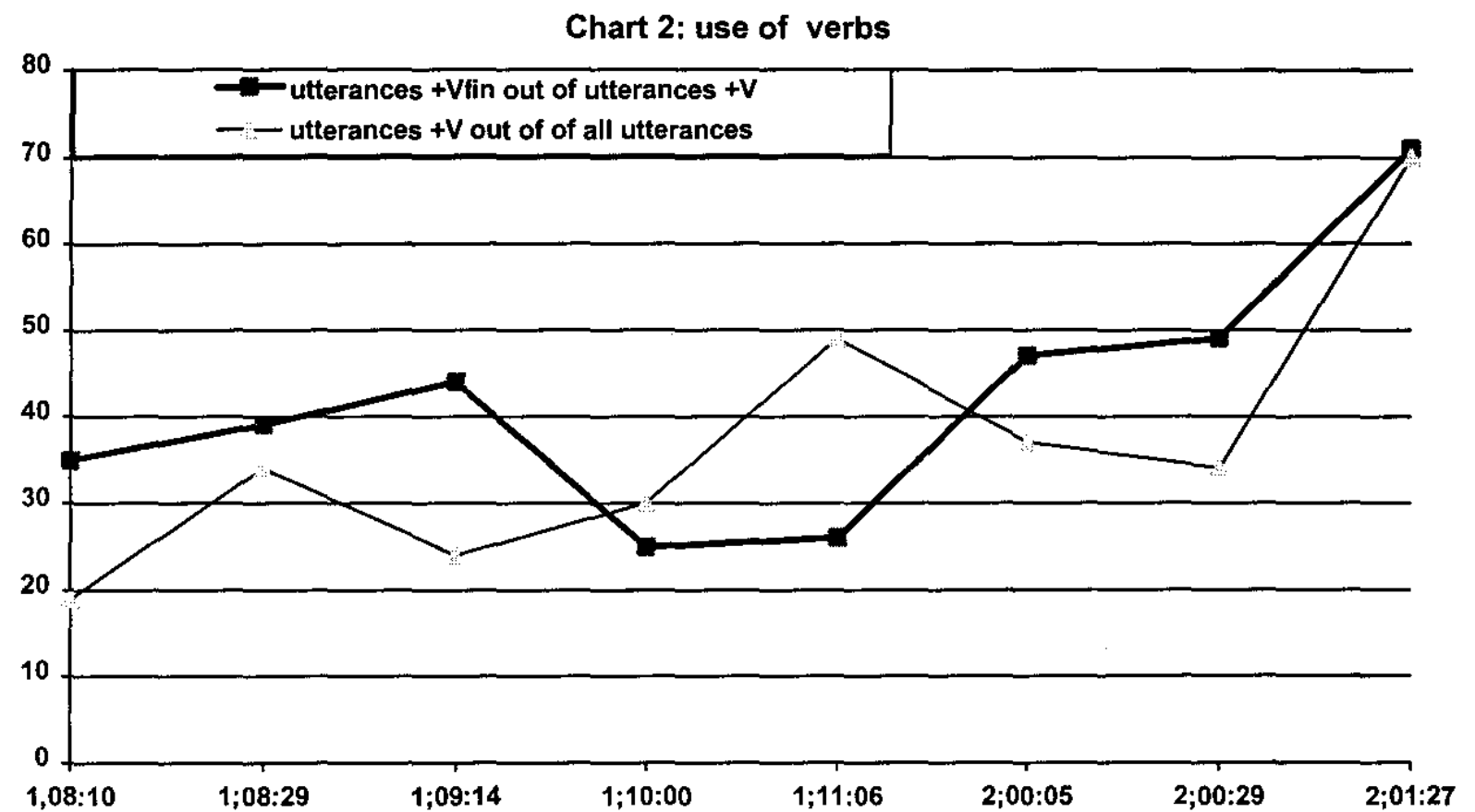

The findings lead to the assumption that the acquisition of finite verbs proceeds by similiar phases as have been found for the acquisition of definite pronouns:

- phase I (1;08:10 - 1;09:06): low amount of utterances with verbs, relatively stable $40 \%$ to $60 \%$ proportion in the use of finite and infinte verbs;

- phase II $(1 ; 10: 00-1 ; 11: 06)$ : increasing amount of utterances with verbs, drastically decreasing of the amount of finite verbs up to $25 \%$;

- phase III $(2 ; 00: 05-2 ; 01: 27)$ : further increase of the amount of utterances with verbs; increasing use of finite verbs starting from $45 \%$ and growing up to $70 \%$;

To understand the observed course of finite verb acquisition a closer look at the finite verbs used in the different recordings is necessary. Table 11 summarizes the emergence of types of verbs Anna uses and how many of them occure in finite form. 
Table 11: number of self-produced verb types per recording

\begin{tabular}{|c|c|c|c|c|c|}
\hline phase & age & $\begin{array}{c}\text { total number of } \\
\text { types }\end{array}$ & $\begin{array}{c}\text { number of types } \\
\text { occuring the first } \\
\text { time }\end{array}$ & $\begin{array}{l}\text { number of finite } \\
\text { verb types }\end{array}$ & $\begin{array}{l}\text { number of finite } \\
\text { verb types occu- } \\
\text { ring the first time }\end{array}$ \\
\hline \multirow[t]{3}{*}{ I } & $1 ; 08: 10$ & 16 & $(16)$ & 3 & (3) \\
\hline & $1 ; 08: 29$ & 18 & 11 & 6 & 4 \\
\hline & $1 ; 09: 14$ & 28 & 18 & 7 & 7 \\
\hline \multirow[t]{2}{*}{ II } & $1 ; 10: 00$ & 26 & 9 & 5 & 1 \\
\hline & $1 ; 11: 06$ & 42 & 22 & 13 & 7 \\
\hline \multirow[t]{3}{*}{ IIII" } & $2 ; 00: 05$ & 39 & 10 & 19 & 7 \\
\hline & $2 ; 00: 29$ & 40 & 16 & 23 & 13 \\
\hline & $2 ; 01: 27$ & 58 & 19 & 52 & 32 \\
\hline
\end{tabular}

In phase I and II Anna uses a relatively stable set of finite verbs as table 11 shows. There are 22 types documented in the recordings. One can assume that these forms are learned by rote learning and are still not members of a verb paradigm. Up to $1 ; 10: 00$ only 4 verbs are used in their infinitive and in their 3.sg.pres. form: machen 'to do', bauen 'built', malen 'draw' and gucken 'look'. As both chart 2 (thin line) and table 11 show there is a spurt in verb acquisition between 1;10:00 and 1;11:06. Nearly 50\% of Anna's utterances in 1;11:06 include a verb; these are $20 \%$ more than in the previous recording. 22 new types of verbs in general and 7 new types of finite verbs are documented. Parallel use of finite and infinite forms of 4 more verbs can be observed: liegen 'lie', gehen 'go', sitzen 'sit', haben 'have'. Nevertheless, the proportion of utterances with finite verbs remains as low as it was in the preceding recording at $1 ; 10: 00$ which is much lower than in the first 3 recordings (cf. chart 2, bold line). How can this apparently paradoxical situation be explained?

What we have to take in to consideration is: additionally to the acquisition of completely new types counted in table 11 a lot of new verbs are formed by prefixation in phase II :

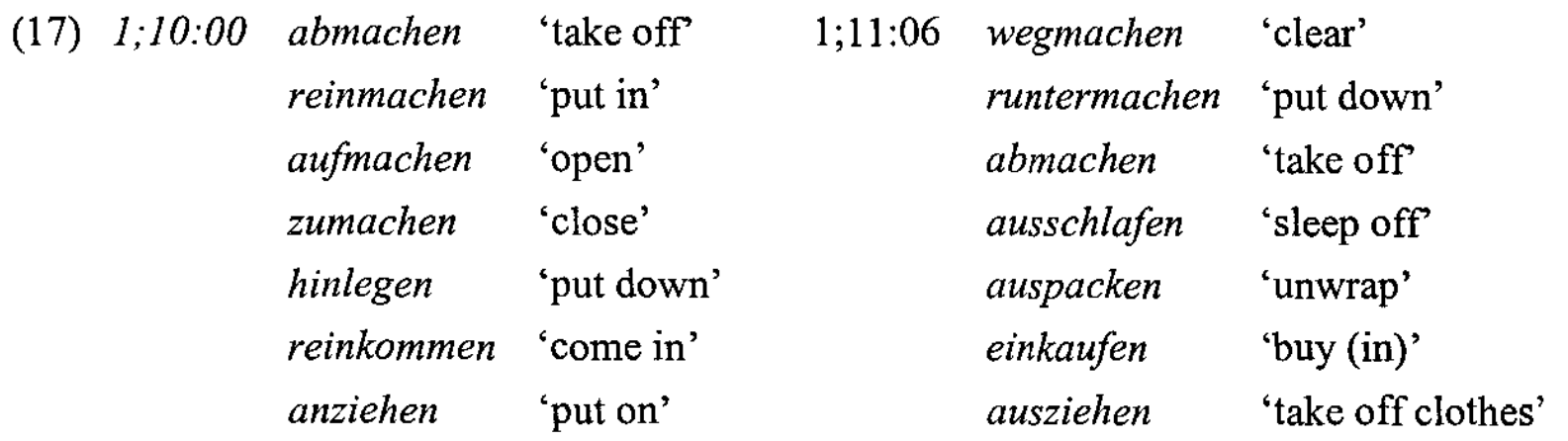

Due to this source of new verbs the verb lexicon is more than doubling in a relatively short period of time. At the end of phase I (at 1;09:14) Anna uses actively around 50 types of verbs. At 1;11:06 this amount is increased up to nearly 100 verbs. This increase in the verb lexicon exceeds the doubling of the finite verb types by far and explains the drop of the finite verb curve (bold line) at 1;10:00 in chart 2 .

The acquisition process reaches a qualitatively new stage after the first three recordings in which Anna is using a relatively small sample of verbs. The concentration lies now on the 
acquisition of new verbs. Probably this is connectected to the acquisition of elementary features of utterance structure. Anna is leaving the one-word-stage which implies the need to build up syntagmatical relations between parts of utterances. She is learning that the verb has a central role in the syntagmatical organization of the utterance. The verb lexicon reaches a critical mass which can no longer be handled by rote learning. It becomes impossible or at least uneconomicaly to store the finite forms of all of these verbs as rote learned lexical forms. The verb system needs a new quality of organization. What is missing in this situation are rules ore general patterns for the creation of appropriate finite verb forms. The reaction we can observe is an overgeneralization of the most common or most unspecified form - the infinitive. New types of finite verbs only rarely occur in comparison to infinite forms, and often the infinite form is used with verbs where a finite form has been produced in earlier recordings.

Increasing use of utterances with verbs, rapid acquisition of new verb types, formation of new verbs by prefixation, preference for the unspecified infinitive verb form are the characteristic features of phase II in verb acquisition. And of course one can observe first steps towards phase III: the beginning of the acquisition of 1.ps.sg. forms and of modal verbs, cf.:

(18) geld hab ich da noch eine hab ich

(19) kann malen einkacken darf puppe nicht
'I have money there'

'I have another one'

'(I) can draw'

'doll must not dirty herself'
$(1 ; 11: 06)$

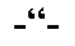

-"

-“-

In phase III then, a clear spurt in the acquisition of types of finite verbs on the one hand and an increase in the frequency of their use in comparison to the infinite verbs on the other hand takes place (cf. table 11 and chart 2). We now find different types of finite verbs, $\mathrm{cf}$.

(20) ich mach das

hamster angucken wollen wir oma ursel war das

(21) glaubich will gucken gehen (ich) du hingehs $(t)$ (nach) hause gehen wollte (kater) wasser gehen die (spielfiguren)

(22) ich bin auch krank du willst auch mit mir bauen? noch was haben wir da sind stifte
'I do that'

'we want to see the hamster' $(2 ; 00: 05)$ 'grandmother ursel was that'

'I think'

'(I) want to go and look' 'you are going where'

'(the cat) wanted to go home' 'they are going (into the) water'

'I am sick too'

'Do you also like to play with me?'

'we do have something else' 'there are crayons'
$(2 ; 01: 27)$ -“-

$(2 ; 00: 29)$

-“-

-“-

-“-

$-“$

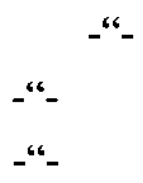


We can call phase III the paradigm building phase. For the purposes of this paper it is not necessary to go into more detail concerning these processes. The crucial thing is that Anna has started to acquire that there is obligatory agreement between the subject element and the verb in the target language or - to say it with other words that the finite verb is an obligatory element of utterances. This process is not finished at $2 ; 01: 27$, but has reached a high level. The verb is finite in $70 \%$ of her utterances including a verb. Because of the fact that there is an amount of structures where the infinite verb is the target structure in adult German the touch of the $100 \%$ mark is not to be expected. But nevertheless, Anna has by no means acquired the target system of agreement at the end of the investigated period. In the acquisition of 2.ps.sg. forms at 2;01:27 the amount of inflected forms is for the first time higher than that of uninflected forms. In questions not formed with a modal verb or an auxiliary Anna still prefers the infinitive form of the verb, $\mathrm{cf}$.

\begin{tabular}{|c|c|c|c|c|}
\hline (23) du heben? & 'you lift (it)?' & vs. & willst haben? & 'do (you) like to have (it)?' \\
\hline du essen? & 'you eat (it)?' & & du mußt auto fahren? & 'you have to drive a car?' \\
\hline du tanzen? & 'you dance?' & & du kannst nicht raus? & 'you can't come out?' \\
\hline
\end{tabular}

Coming back to the question of possible correlations of the acquisition of definite pronouns and finite verbs one can notice that we found a parallel increase in the occurence of definite pronouns and of finite verbs in phase III. The next chapter gives a brief discussion of the correlations.

\section{Correlations in the acquisition of definite pronouns and finite verbs}

Productive use of definite pronouns starts in phase II with the deictic use of das. Only 3 of 21 $(1 ; 10: 00)$ and 2 of $22(1 ; 11: 06)$ definite pronouns are other forms than das in this phase. More important, only 1 of these 21 and 2 of these 22 definite pronouns occure in utterances containig a finite verb - and these are in both recordings one times der. Chart 3 demonstrates the development of the use of finite verbs in Anna's utterances (bold line) and the occurence of definite pronouns in these utterances (broken line). Utterances with frozen and imitated finite verb phrases, imperatives, and bare participles are excluded from the counting. 


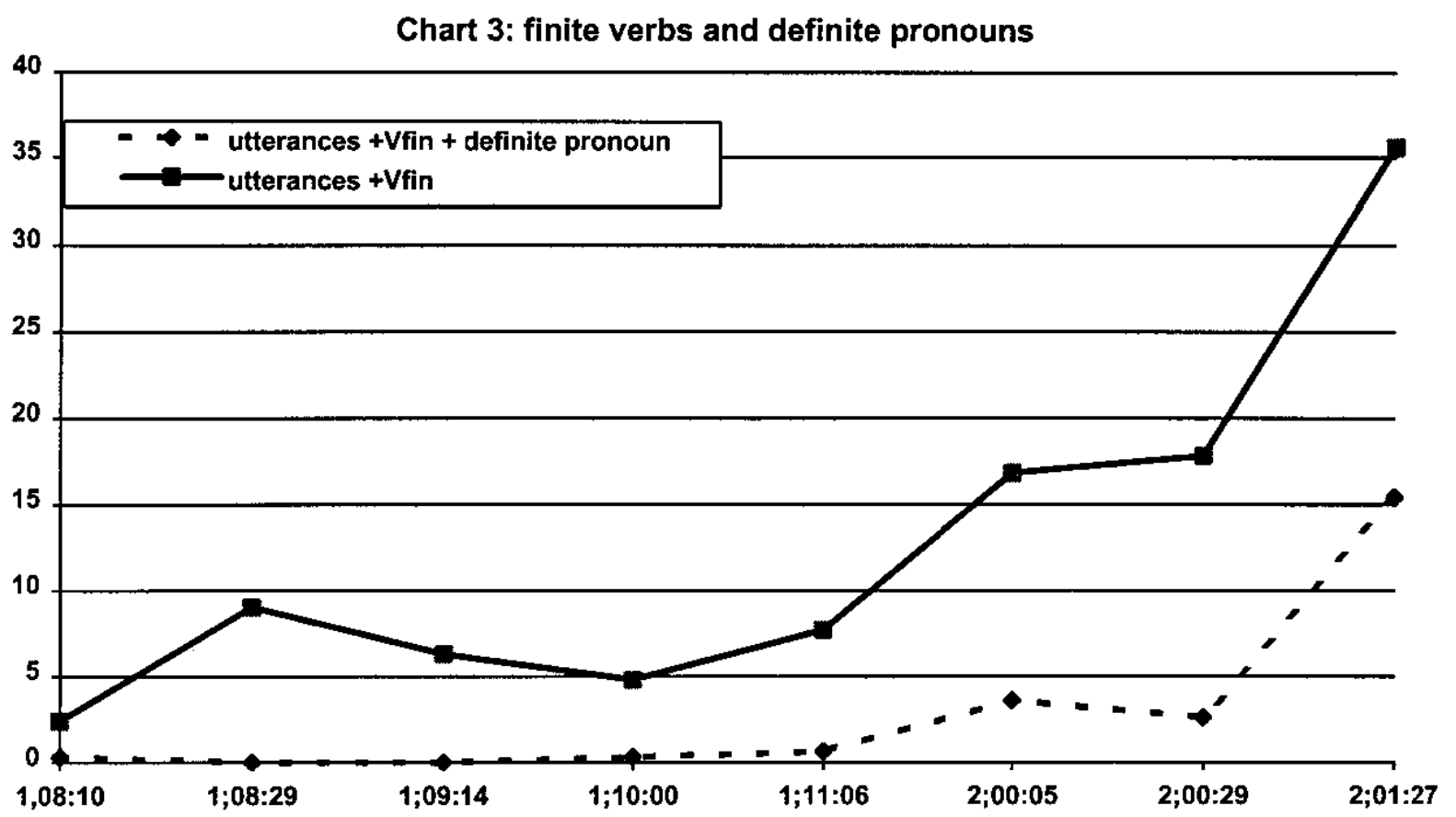

In 2:00:29 $75 \%$ of all definite pronouns occure in utterances containing a verb, $55 \%$ in utterances with finite verbs. Nearly $70 \%$ (11 of 16) of definite pronouns in the latter are die or der. It becomes obvious that phase III is characterized by the acquisition of die and der as verb related definite pronouns ${ }^{12}$, cf. tables 4-6. In utterances containing a finite verb der occures always in the subject position, die predominantly in the subject position but as well in the object position as it is the case in adult grammar.

From 2;01:27 on also das is used in verb related structural positions. On the one hand Anna has extended its use for general reference relations to copula constructions where no specific thematic element is required, cf. das ist mein bett 'it is my bed'. On the other hand she starts to use das as element for unconcrete reference relations in subject and object positions. The acquisition of das as an element for concrete reference relations has not started yet.

If we take in to consideration that Anna's data show a spurt in the use and acquisition of finite verbs between 1;11:06 and 2;00:05 one can assume that this process is the trigger for the acquisition of such definite pronominals which can fullfil structural requirements of utterances with finite verbs. This leads to a differentiation of the system of definite pronominals from a one element system (das) to functional specified system (der, die, das).

To understand this correlation in the acquisition process we should think of the fact that the acquisition of agreement is based on the relation between a nominal element and the verb as the core of the predication - as well as think of the fact that German is not a pro drop language, which means that the child learns from the input that the finite verb should be

12 In 2;00:29 there are 4 other die/der forms in utterances with infinite verbs. With two other cases these are the only occurencies of these forms in utterances with infinite verbs and could be regarded at the moment as the exceptions which confirm the rule. 
accompanied by an agreeing subject element. To acquire person/number agreement in German is - due to the input - closely related to the acquisition of subject elements. Because of that we will briefly look at Anna's acquisition of subject elements.

\section{Acquisition of subject elements}

Table 12 givs an overview of the subject elements used by Anna in the investigated recordings, not counted are utterances with frozen patterns, imitated subjects, and imperatives.

Table 12: Anna's use of subject elements

\begin{tabular}{|c|c|c|c|c|c|c|}
\hline phase & age & proper name & $\begin{array}{l}\text { personal } \\
\text { pronoun }\end{array}$ & $\begin{array}{l}\text { definite } \\
\text { pronoun }\end{array}$ & $\begin{array}{c}\text { noun } \\
\text { element }\end{array}$ & $\begin{array}{l}\% \text { of utte- } \\
\text { rances }+V\end{array}$ \\
\hline \multirow[t]{3}{*}{ I } & $1 ; 08: 10$ & 2 & & 1 & & 13 \\
\hline & $1 ; 08: 29$ & 5 & 2 & 1 & & 14 \\
\hline & $1 ; 09: 14$ & 1 & 1 & 2 & & 9 \\
\hline \multirow[t]{2}{*}{ III } & $1 ; 10: 00$ & 2 & 1 & 2 & 1 & 9 \\
\hline & 1;11:06 & 9 & 5 & 1 & 8 & 16 \\
\hline \multirow[t]{3}{*}{ IIII } & $2 ; 00: 05$ & 3 & 11 & 3 & 8 & 20 \\
\hline & $2 ; 00: 29$ & 14 & 46 & 11 & 16 & 37 \\
\hline & $2 ; 01: 27$ & 19 & 75 & 38 & 25 & 50 \\
\hline
\end{tabular}

What this table shows is that the use of subject elements becomes productive from 2;00:05 on. This is at the time we found the spurt of finite verbs. The source of the increase of subject elements is mainly related to the increase in the use of pronouns like $I$, you and we and the increase in the use of the definite pronouns, especially of der and die.

\section{Final preliminary conclusions}

Finally I will briefly discuss possible conclusions of the presented analyses. All statements can only be preliminary because they are based on the analysis of only one child and have to be verified by the data of other children.

The hypothesis of the present study was: the acquisition of finite verbs triggers the acquisition of definite pronouns in German.

The first definite pronoun Anna acquires is the form das. Das has been acquired to refer to elements (single or complex ones) given in the communicative context. The grammatical function of das in this early period could be understood as the symbolization of the feature [+deictic]. This feature implies the feature [+known] which is characteristic for all definite pronouns. During the time in which das is acquired Anna does not use finite verbs productively, i.e. she has not acquired the paradigmatic contrast between infinite and finite verbs.

More than 4 months later Anna acquires the definite pronouns der and die. In the meantime she has started to use finite verbs productively. Likeweise the complexity of utterance 
structure has grown. Anna has started to develop an utterance structure which includes a verb as an obligatory element and one or two verb dependend constituents. Additionally Anna is now able to communicate about things not directly present in the actual situation. ${ }^{13}$

While the acquisition of das in its purely deictic function is not related to aspects of verb and utterance structure the acquisition of der and die seems to be related to these processes. As mentioned above the child has learned (cf. 3.4) that the deictic demonstrative das is not target like in all contexts.

The main trigger for the acquisition of $d e r$ and die seems to be that the child acquires that the reference relation provided by definite pronouns has to be specified according to agreement features: a feature which is not part of the meaning of the form das in its early acquisition - and which can not be realised by a single form. The point in acquisition where agreement occurs as an regular or obligatory requirement is the acquisition of the finite verb as an obligatory element of utterance structure. As already mentioned this is why German is not a pro drop language.

The acquisition of the finite verb is closely related to the acquisition of obligatory use of the noun phrase which is in subject position. As could be shown in chapter 6 , subject elements occur in the data of Anna with noticable frequency when she starts to use finite verbs productively. Up to $2 ; 01: 27$ definite pronouns become more and more important in the function of subject elements as table 12 shows. Since we assume that this is due to the increasing complexity of utterances. Thematic elements which could take the subject position are no longer primarily proper names and personal pronouns which have deictic reference but definite pronouns and to some extent nominal phrases containing a noun which could refer as well to elements of the language context, e.g. elements with an anaphorical potential. These elements have to fulfill agreement requirements.

Finally we can assume that primarily two aspects trigger the acquisition of the differentiated inventory of definite pronouns (e.g. of der, die, and at least of the anaphoric use of das):

- the acquisition of the finite verb - triggering the acquisition of obligatory use of subject elements which have to be in agreement with the finite verb, and related to the acquisition of the finite verb

- the acquisition of a complex utterance structure which requires the distinction between new and old information and the reference to former elements of the language context.

The early acquisition of definite pronouns - be reminded that they are acquired before complex noun phrases and the use of articles - probably could be explained by their advantage of being structurally minimally complex. Rather than spending much of her restricted capacities for the construction of phrases and their combination on the construction of the already known subject phrase the child can use these simple elements.

13 For instance, in the recording at 2;00:05 Anna starts to talk on her own about her grandparents and other relatives. 


\section{Bibliography}

Behrens, Heike (1993), Temporal reference in German child language. Form and function of early verb use. Den Haag: CIP-Gegevens Koninkliijke Bibliotheek.

Bittner, Dagmar (1998), Entfaltung grammatischer Relationen im NP-Erwerb: Referenz. In: Folia Linguistica XXXI/3-4 (C). 255-283.

Clahsen, Harald (1991), Child Language and Developmental Dysphasia. Amsterdam/Philadelphia: Benjamins.

Clahsen, Harald et al (1993), Clahsen, Harald/Martina Penke/Teresa Parodi: Functional Categories in Early Child German. Language Acquisition 3. 395-429.

- (1994), Clahsen, Harald/Sonja Eisenbeiß/Anne Vainikka: The Seeds of the Structure: A Syntactic Analysis of the Acquisition of Case Marking. In: Hoeckstra, Teun/Bonnie D. Schwartz (eds), Language Acquisition in Generative Grammar. Amsterdam/Philadelphia: Benjamins. 85-118.

Meisel, Jürgen (1990), INFL-ection: Subjects and subject-verb agreement. In: Meisel, J.M. (ed.); Two first languages. Dordrecht: Foris, 237-298.

Mills, Anne E. (1985), The Acquisition of German. In: Slobin, Dan I. (ed)., The crosslinguistic study of language acquisition, Vol. I: The Data. Hillsdale, NJ: Lawrence Erlbaum. 141-254.

- (1986), The acquisition of Gender. A study of English and German. Berlin/Heidelberg/ Paris/New York/Tokio/London: Springer.

Müller, Natascha (1994), Gender and Number Agreement within DP. In: Meisel, Jürgen M. (ed.), Bilingual First Language Aquisition. French and German Grammatical Development. Amsterdam: Benjamins

- (1999), Gender and number in acquisition. In: Unterbeck, Barbara/Matti Rissanen (eds), Gender in Grammar and Cognition, Vol. I: Approaches to Gender. Berlin: Mouton/de Gruyter. 351-400.

Schlyter, Susanne (1990), The acquisition of tense and aspect. In: Meisel, J.M. (ed.); Two first languages. Dordrecht: Foris, 87-121. 